\title{
Blast Performance of Sandwich Composites with In-Plane Compressive Loading
}

\author{
E. Wang • A. Shukla
}

Received: 13 December 2010 / Accepted: 12 April 2011

(C) Society for Experimental Mechanics 2011

\begin{abstract}
An experimental investigation was conducted to evaluate the dynamic performance of E-glass Vinyl Ester composite face sheet / foam core sandwich panels when subjected to pre-compression and subsequent blast loading. The sandwich panels were subjected to $0 \mathrm{kN}, 15 \mathrm{kN}$ and $25 \mathrm{kN}$ of in plane compression respectively, prior to transverse blast wave loading with peak incident pressure of $1 \mathrm{MPa}$ and velocity of 3 Mach. The blast loading was generated using a shock tube facility. During the experiments, a high-speed photographic system utilizing three digital cameras was used to acquire the real-time 3-D deformation of the sandwich panels. The 3D Digital Image Correlation (DIC) technique was used to quantify the back face out-of-plane deflection and in-plane strain. The results showed that in-plane compressive loading facilitated buckling and failure in the front face sheet. This mechanism greatly reduced the blast resistance of sandwich composites.
\end{abstract}

Keywords Sandwich structures · Blast loading · High speed photography · Digital image correlation · Buckling

\section{Introduction}

Sandwich composites have many important applications in the naval, aerospace, transportation and defense industries

E. Wang (SEM member)

Department of Aerospace Engineering,

University of Illinois at Urbana-Champaign,

Urbana, IL 61801, USA

\author{
A. Shukla ( $₫$, SEM Fellow) \\ Department of Mechanical, Industrial and Systems Engineering, \\ University of Rhode Island, \\ Kingston, RI 02881, USA \\ e-mail: shuklaa@egr.uri.edu
}

due to their several advantages, such as high strength/ weight ratios, high stiffness/weight ratios, and high energy absorption capabilities. In many of these applications, sandwich composites are subject to an initial in-plane compressive loading. For example, a ship's hull will undergo longitudinal (in-plane) compressive loading during its service life [1], a missile's shell will suffer in-plane inertia force when it is launched, and some residual stresses may be present in composites from manufacturing and assembling processes. When these pre-loaded composites are subjected to high-intensity transverse impulse loadings such as air blasts, the coupling of the in-plane pre-load and transverse blast loading will likely affect their blast mitigation performance.

However, recent investigations on the behaviors of sandwich composites under blast loading mainly focus on the transverse behavior without longitudinal compressive loading [2-8]. Nurick [2], Zhu [3], and Dharmasena et al. [4] have tested sandwich structures with a metallic honeycomb core. Radford et al. [5] conducted blast experiments on sandwich composites with a metal foam core. They all found that the ability of sandwich panels to resist dynamic loading is far superior to that of monolithic metal plates with the same areal density. Tekalur et al. [6] have studied the blast performance of sandwich structures with reinforced polymer foam cores. They concluded that the imparted damage was substantially reduced when Zdirection pin reinforcements (through thickness direction) were introduced into the core material. Wang et al. [7] constructed a sandwich structure with stepwise graded core materials and subjected it to transverse blast loading. They found that monotonically increasing the wave impedance of the core layers enhanced the blast resistance of the sandwich structures. Many of the above results have been summarized in Ref [8]. 
Some investigations on the dynamic response of prestressed composite structures under low-velocity transverse impact loadings can be found in literature [9-13]. Robb et al. [9] carried out the first experimental investigation on the low-velocity impact response of E-Glass reinforced/polyester laminated plates under different in-plane uni-axial and biaxial pre-stress. They found that the effects of the prestress were significant only at the highest level of pre-stress (equivalent to $6,000 \mu \varepsilon$ ) and the shear loading produced the greatest impact damage area on the specimen. Whittingham et al. [10] performed similar experiments on carbon-fiber/ epoxy laminated plates under tensile and shear pre-stress. They also found that low pre-stress levels $(<1,500 \mu \varepsilon)$ had no significant effect on the peak force of impact, absorbed energies and penetration behavior. Heimbs et al. [11] tested carbon-fiber/epoxy laminated plates under an in-plane compressive pre-load. An increase in deflection and energy absorption was observed under a pre-load of $80 \%$ of the buckling load. Sun et al. [12] and Choi [13] analytically investigated the effects of pre-stress on the dynamic response of composite laminates. They found that the initial in-plane tensile load increased the peak contact force while reducing the total contact duration and deflection. The compressive load reacted oppositely. However, contact loading, such as impact loading, will induce localized damage, which is different from air or underwater blast loading. Thus, these results cannot be extended to the blast response of composite structures.

There are very few theoretical and numerical studies [14, 15] related to the blast response of pre-loaded structures. Experimental investigations on pre-loaded composite materials under blast loading have not been conducted. The absence of experimental data of pre-stressed structures under blast loading also makes it difficult to verify the numerical models. Therefore, there is a critical need to investigate the effect of compressive loading on the dynamic behavior of composite materials under blast loading.

The present study focuses on the dynamic behavior and failure mechanisms of sandwich composites with in-plane compressive loading when experimentally subjected to a transverse blast loading (as shown in Fig. 1). The buckling loads of sandwich panels under different buckling modes were first calculated theoretically. Three compressive loading levels were chosen based upon the theoretical estimations of buckling loads. These compressive loadings were implemented using a specially designed fixture, to allow for different static in-plane compressive loadings on the sandwich panels prior to transverse blast loading. A high-speed photography system with three cameras was utilized to capture real-time images of the panel during blast loading. 3-D Digital Image Correlation (DIC) techniques were utilized to obtain the full field data of the
Fig. 1 A sketch of a blast loading upon a structure with in-plane compressive loading

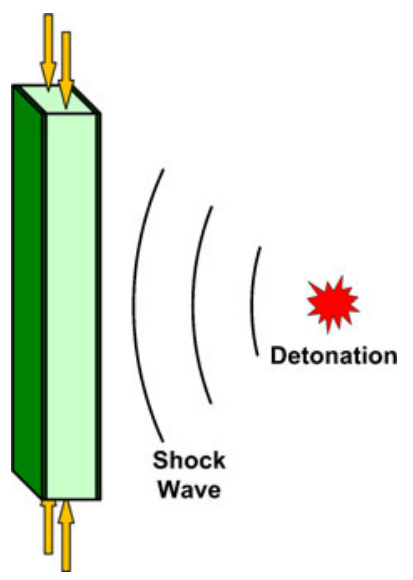

deformation during the blast events. Post mortem visual observations of the test samples were also carried out to indentify the failure modes. The results showed that inplane compressive loading facilitated buckling and failure in the front face. This mechanism greatly reduced the blast resistance of the sandwich composites.

\section{Material and Specimen}

The sandwich specimen used in this study and its dimensions are shown in Fig. 2. The VARTM (Vacuum Assisted Resin Transfer Molding) procedure was carried out to fabricate sandwich composite panels. The overall dimensions for the specimen were $102 \mathrm{~mm}$ wide, $254 \mathrm{~mm}$ long and $33 \mathrm{~mm}$ thick. The foam core itself was $25.4 \mathrm{~mm}$ thick, while the skin thickness was $3.8 \mathrm{~mm}$. The average areal density of the samples was $17.15 \mathrm{~kg} / \mathrm{m}^{2}$.

The sandwich skin material was E-Glass Vinyl Ester (EVE) composite. The woven roving E-glass fibers of the skin material were placed in a quasi-isotropic layout $[0 / 45 /$ $90 /-45]_{\mathrm{s}}$. The fibers were made of a $0.61 \mathrm{~kg} / \mathrm{m}^{2}\left(18 \mathrm{oz} / \mathrm{yd}^{2}\right)$ area density plain weave. Ashland Derakane Momentum 8084 resin was used as the matrix material, and the front and back skins consisted of identical layup and materials. The core material used in the present study was Corecell ${ }^{\mathrm{TM}} \mathrm{P} 600$ styrene foam (manufactured by Gurit SP Technologies). Table 1 gives the material properties of the face-sheet that were determined using ASTM standard tests and the manufacturer's property data for P600 foam [16].

\section{Determination of In-plane Compressive Loading for Sandwich Composites}

In-plane Buckling of Sandwich Composites

The in-plane buckling behavior of sandwich composites has been studied for years $[17,18]$. There are three main 


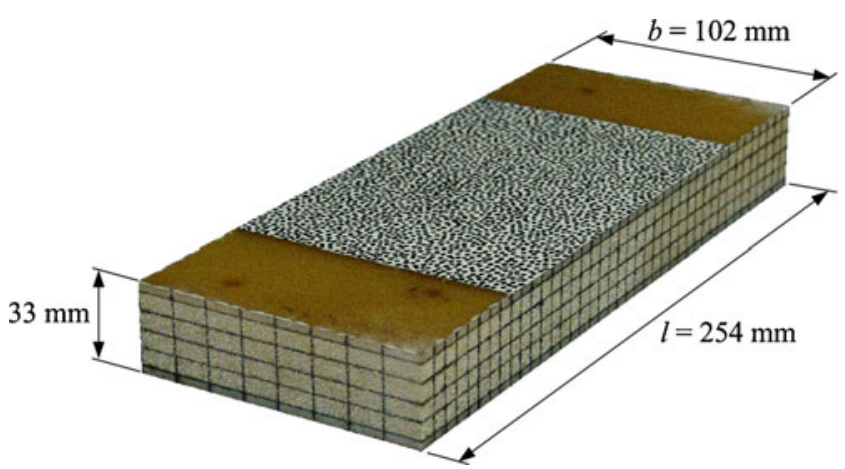

Fig. 2 The sandwich specimen and over all dimensions

buckling modes based on the geometries and materials [17]: elastic buckling in bending and shear (global buckling), plastic micro-buckling of the face sheets and face wrinkling (as shown in Fig. 3).

Consider a sandwich composite with face sheet thickness $t$, core thickness $c$, total width $b$ and total length $l$. The face sheet material has an in-plane Young's modulus $E_{f}$ and inplane yield strength $\sigma_{f y}$. The core material has a Young's modulus $E_{f}$ and shear modulus $G_{c}$. For elastic buckling in bending and in shear (global buckling), the critical buckling load $P_{c r}^{g b}$ is [17],

$P_{c r}^{g b}=\frac{P_{E} P_{s}}{P_{E}+P_{s}}$

where, $P_{E}=\frac{4 \pi^{2}(E I)_{e q}}{l^{2}}$ is the Euler buckling load and $P_{S}=$ $b c G_{c}$ is core shear buckling load. $(E I)_{\mathrm{eq}}$ is the bending stiffness of the sandwich panel,

$(E I)_{e q} \approx \frac{b t c^{2} E_{f}}{2}$

For plastic micro-buckling of the face sheets, the critical buckling load $P_{c r}^{f f}$ is [17],

$P_{c r}^{f f}=2 b t \sigma_{f y}$

where, $t$ is the thickness of the face sheets.

Table 1 Material properties of the components in sandwich composites

\begin{tabular}{ll}
\hline Materials & Properties \\
\hline E-glass Vinyl Ester composite & Nominal density: $1,800 \mathrm{~kg} / \mathrm{m}^{3}$ \\
& Compressive modulus: $13.6 \mathrm{GPa}$ \\
& Compression strength: $220 \mathrm{MPa}$ \\
CoreCell & Nominal density: $122 \mathrm{~kg} / \mathrm{m}^{3}$ \\
& Compressive modulus: $125 \mathrm{MPa}$ \\
& Compression strength: $1.81 \mathrm{MPa}$ \\
& Shear modulus: $56 \mathrm{MPa}$ \\
\hline
\end{tabular}
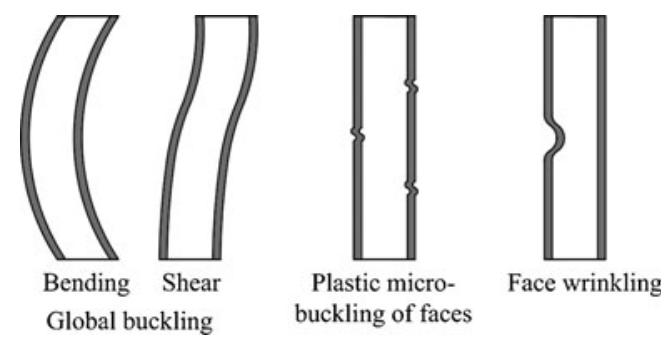

Fig. 3 In-plane buckling modes of sandwich composites

For face wrinkling, the critical buckling load $P_{c r}^{f w}$ is [17],

$P_{c r}^{f w}=0.5 b t\left(\sqrt[3]{E_{f} E_{c} G_{c}}\right)$

In-plane Compressive Loads

Using the parameters of the sandwich composites described in Material and Specimen section, one can obtain the critical buckling load at each mode. Since the applied compressive loading is static, we use the quasistatic properties of the material in determining the buckling loads. The buckling loads are listed in Table 2 . Therefore, the mode at which the sandwich panel is most likely to fail is plastic micro-buckling of the face sheets. Based on the critical buckling load $76 \mathrm{kN}$, three different in-plane compressive loading levels were chosen for the present study: $0 \mathrm{kN}$ (no loading), $15 \mathrm{kN}(\sim 20 \%$ of critical buckling load) and $25 \mathrm{kN}(\sim 33 \%$ of critical buckling load).

\section{Experimental Setup and Procedure}

\section{Shock Tube}

A shock tube apparatus was utilized to obtain a controlled blast loading. The details of this apparatus can be found in Ref. [7]. Figure 4 shows the shock tube apparatus and a detailed view of the muzzle end. The muzzle inner diameter is $76.2 \mathrm{~mm}$. Two high frequency response pressure transducers (PCB102A) are mounted at the end of the muzzle section with a distance of $160 \mathrm{~mm}$ between them. The support fixtures ensure simply supported boundary conditions with a $152.4 \mathrm{~mm}$ span.

\section{In-plane Compressive Loading Fixture}

The fixture used to apply the in-plane static compression loading on the sandwich composite panels is shown in Fig. 5. The loading head is connected to a hydraulic loading cylinder, which is mounted on the frame. An aluminium cylinder with an outer-diameter of $\varnothing 50.8 \mathrm{~mm}$ and an inner- 
Table 2 Critical buckling load at different buckling mode
Buckling mode

Critical buckling load $(\mathrm{kN})$

Elastic buckling in bending and in shear (global buckling)

128

Plastic micro-buckling of the face sheets

76

Face wrinkling
147 diameter of $\varnothing 38.1 \mathrm{~mm}$ is positioned between two plates as shown in Fig. 5(b). Two strain gages, which are attached on this aluminium cylinder, measure the deformation of this cylinder and consequently provide the load applied on the specimen. The support fixture and in-plane compressive loading fixture are all securely fastened inside the dump tank of the shock tube.

\section{High-speed Photography Systems}

Two high-speed photography systems were utilized to capture the real-time 3-D deformation data of the specimen. Figure 6 shows the experimental setup. It consisted of a back-view 3-D Digital Image Correlation (DIC) system with two cameras and a side-view camera. The cameras are Photron SA1 digital cameras, which can capture images at a frame rate of 20,000 fps with an image resolution of $512 \times$ 512 pixels for $1 \mathrm{~s}$ time duration. These cameras were synchronized to ensure that the images and data can be correlated and compared.

The 3-D DIC technique is one of the most recent noncontact methods for analyzing full-field shape, motion and deformation. The working mechanism of this technique is similar to how our eyes function. Two cameras capture two images from different angles at the same time. By correlating these two images, one can obtain the three dimensional shape of the surface. Correlating this deformed shape to a reference (zeroload) shape gives full-field in-plane and out-of-plane deformations. The details of this technique can be found in Ref. [19-22]. In the present study, Vic-3D DIC software from Correlation Solution, Inc was utilized to analyze the high-speed images. To ensure good image quality, a speckle pattern with good contrast was put on the specimen prior to experiments.

\section{Experimental Procedure}

The in-plane compression loading was applied on the specimen and held at a constant level until the specimen was subjected to the transverse shock wave loading. The loading head is fixed during the whole experimental process. The load will be released when the vertical dimension of the specimen is reduced. For each compression loading, at least two samples were tested to ensure repeatability. The high-speed photography systems and the pressure sensors were synchronized and were triggered to record the pressure data and deformation images upon the arrival of shock wave.

\section{Experimental Results and Discussion}

\section{Real-time Side-view Deformation Images and Deflection}

A typical pressure profile obtained from the transducer closest to the specimen during blast loading from the shock tube is shown in Fig. 7. The incoming shock wave has an incident peak pressure of approximately $1 \mathrm{MPa}$, and a wave velocity of approximately 1,000 m/s ( Mach 3$)$. This shock wave reflects from the specimen with an approximate peak pressure of 4.7 $\mathrm{MPa}$ and an approximate reflected velocity of $350 \mathrm{~m} / \mathrm{s}$. For a more detailed analysis of the pressure data, refer to Ref. [23].

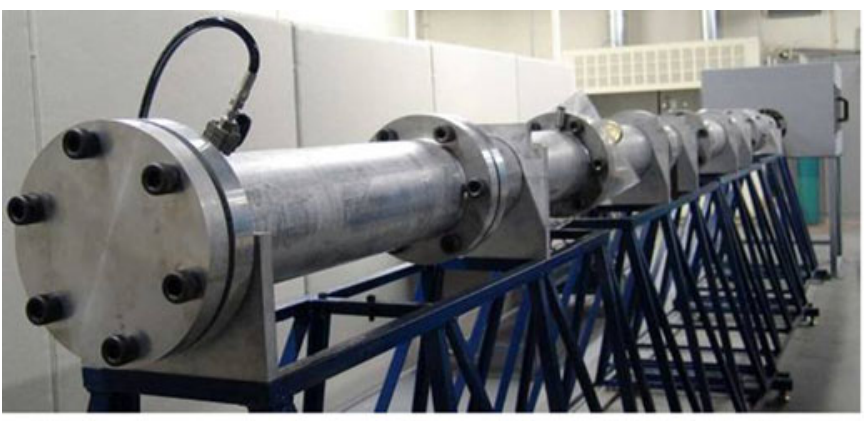

(a) Shock tube

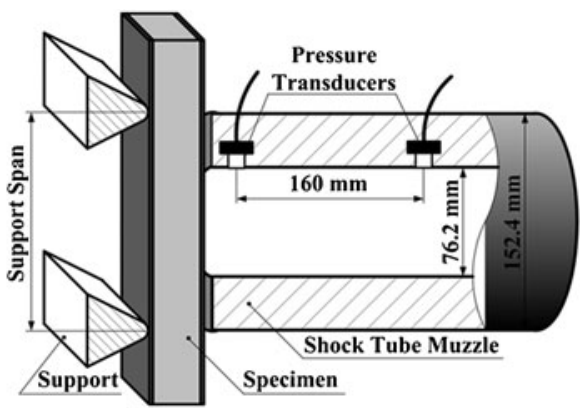

(b) Dimension of the muzzle end

Fig. 4 Shock tube apparatus 
Fig. 5 in-plane compressive loading fixture

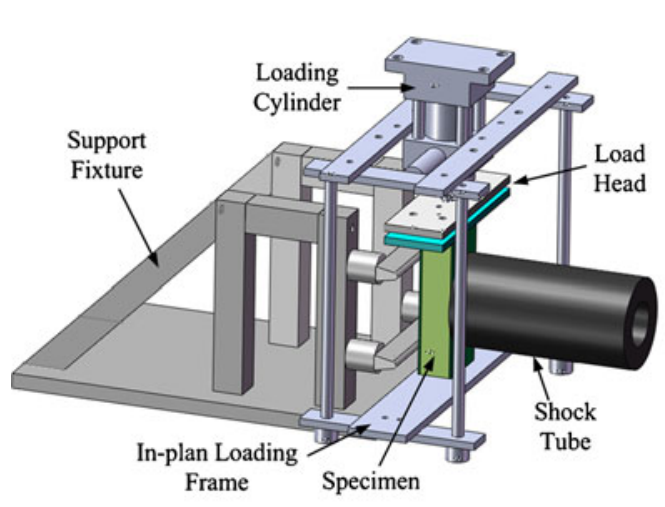

(a) Fixture assembling

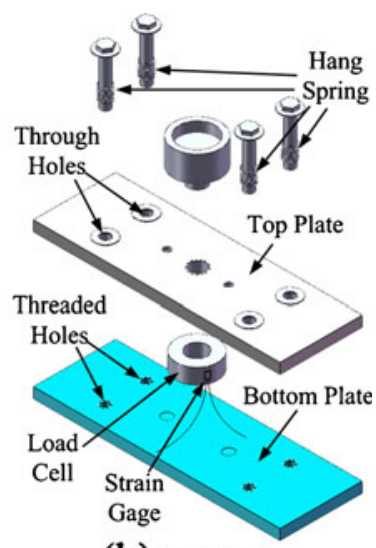

(b) Load head
Real-time Side-view Deformation Images and Deflection

The real time side-view images of sandwich composites subjected to the same amplitude and duration of the incoming blast wave and with different levels of initial compressive loading on them are shown in Fig. 8. The shock wave propagates from the right side of the image to the left side. Some deformation details are pointed out on the images.

From the images, it can be clearly seen that the initial deformation modes for the sandwich composite with different levels of compressive loading are very similar. Prior to $400 \mu \mathrm{s}$ all the specimens show global bending with a typical double wing shape, which means that the core is under intense shear loading. At almost $350 \mu \mathrm{s}$ after shock loading, shear cracks in the core begin to emerge in specimens with no in-plane loading $(0 \mathrm{kN})$. The in-plane compressive loading tends to suppress the formation of core cracks. In the specimens with $15 \mathrm{kN}$ and $25 \mathrm{kN}$ in-plane loading, the shear cracks in the core only begin to appear around $1,200 \mu \mathrm{s}$ and $900 \mu \mathrm{s}$ respectively.

The deformation modes of the specimens with different in-plane loadings also change after $400 \mu \mathrm{s}$. The specimen

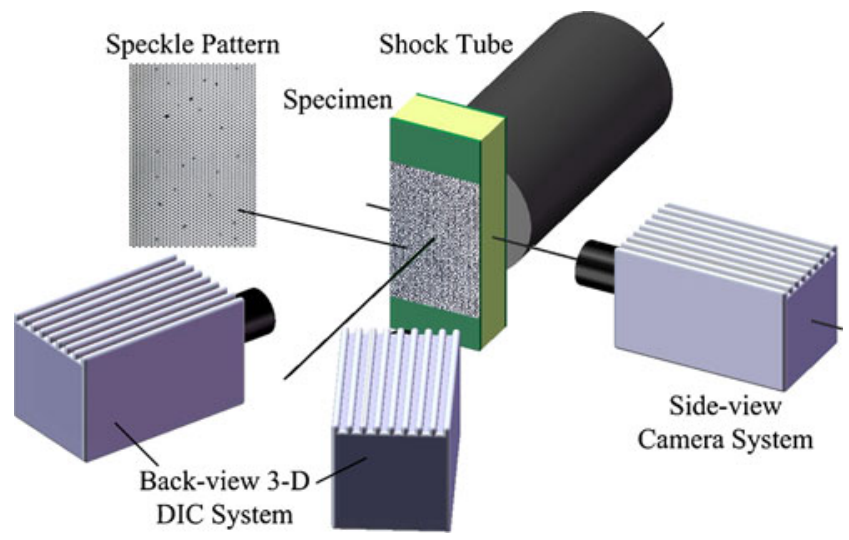

Fig. 6 High-speed photography systems without in-plane loading $(0 \mathrm{kN})$ continues bending symmetrically. The front face-sheet shows a profile with a smooth curvature, implying no local buckling in the front face. For the specimen with the $15 \mathrm{kN}$ compressive loading, the initial deformation with a symmetric profile shifts to an asymmetric mode. The section of the front face-sheet close to the lower support exhibits more curvature than the section close to the upper support. This asymmetrical phenomenon indicates that there is local buckling at the lower section of the front face-sheet. At approximately $1,600 \mu \mathrm{s}$, the debonding of the front face-sheet from the core gives clear evidence of local buckling (shown by the white circle). Meanwhile, the curved profile in the middle section (right above the local buckling position) of the front face sheet changes to a flat profile, indicating that the bending moment applied on this section has been released. For the specimen with the $25 \mathrm{kN}$ compressive loading, there are two obvious kinks in the front face-sheet (shown by the white circle). The middle section has a flat profile between two kinks implying that there are two failure hinges at kink positions and these failure hinges release the moment applied on this section. These two failure hinges are induced by local buckling in the face sheet. From the photographs it can also be seen that kink formation occurs

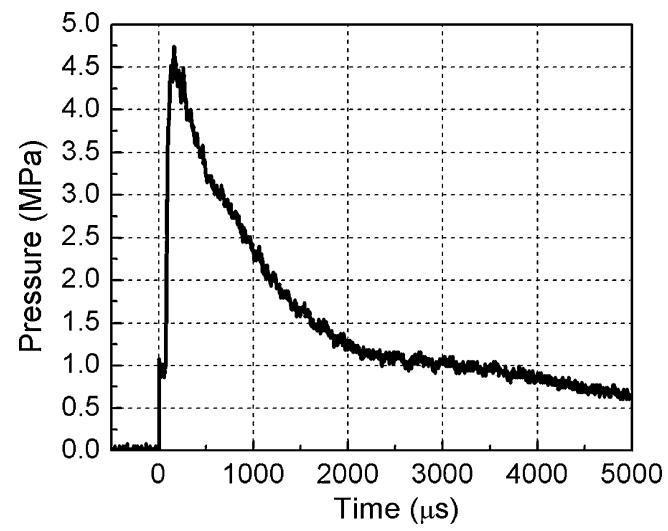

Fig. 7 Typical pressure profile from transducer 2 
Fig. 8 Real time side-view deformation of sandwich composites with initial compressive loadings

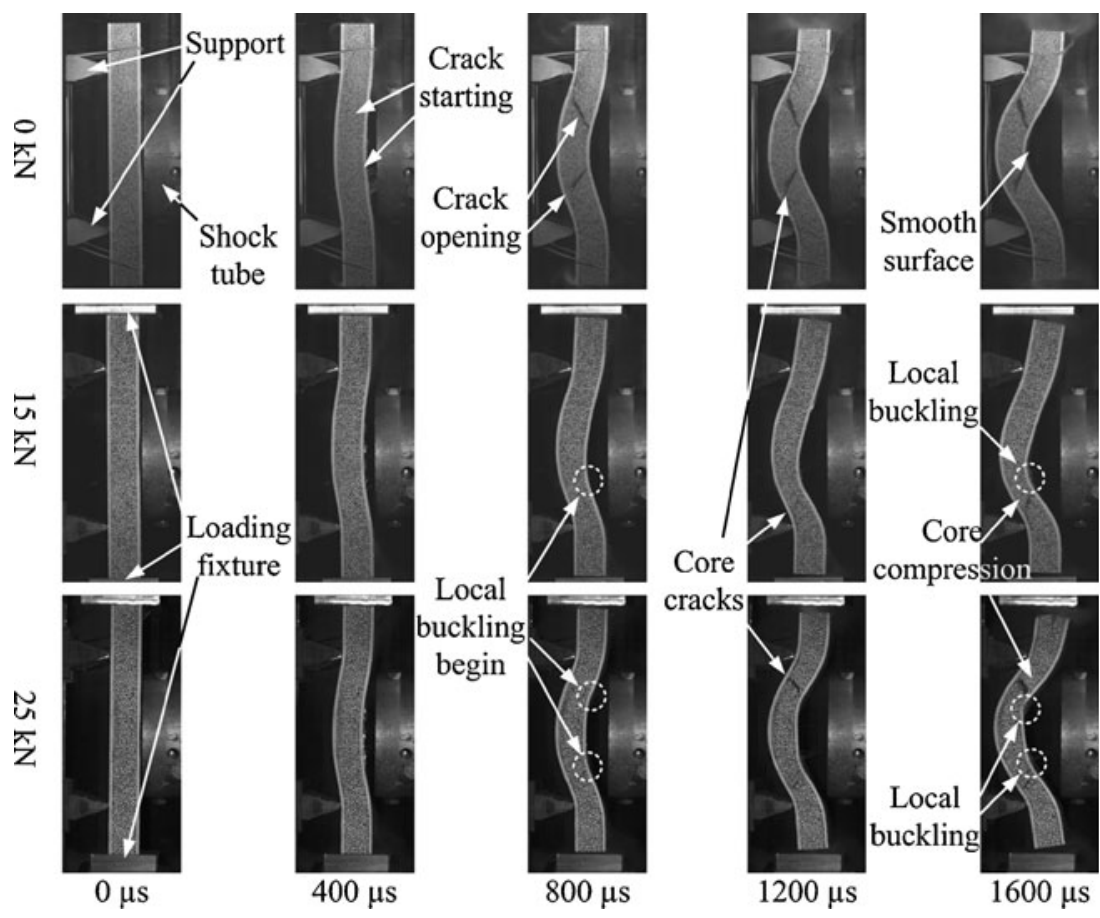

earlier in specimens with larger in-plane compressive loading.

On the other hand, the deformation behaviors of the back face sheets for all sandwich panels are similar. They all show smooth curvatures, indicating there is no buckling in the back face sheet. This is because the shock loading does not apply on the back face directly. As mentioned in Ref. [24], the motion of the sandwich structure starts from the front face sheet upon which the shock loading is directly applied. The load is only transmitted to the back face sheet after the stress wave has passed through the core and the core is compressed. This implies two facts. First, the load applied on the back face gets dispersed as it transmits through the core, and as such will not be concentrated. Second, the intensity of load transmitted to the back face depends on the core compressive properties. As the core foam material has a long low-level stress plateau in its constitutive behavior, the load applied on the back face will be much lower than the shock loading applied directly on the front face. Therefore, the combined effect of the inplane compressive loading and the local transverse shock wave loading (as discussed in depth in Post Mortem Analysis section), only changes the global and local deformation behavior of the front face.

It needs to be noted that in Fig. 8 the ends of the specimen without in-plane loading almost do not rotate in the very beginning (before $400 \mu \mathrm{s}$ ). This indicates that the flat loading head will probably not constrain the end rotation of the specimens when applying the in-plane compressive loading. After $400 \mu \mathrm{s}$, the ends of the specimens with in-plane loadings actually disconnect from the loading head. The position of the loading head remains fixed, whereas the vertical dimension of the specimen shrinks due to global bending. Therefore, the constraint of end rotation is minimized in the present study and the simply supported boundary as mentioned in Shock Tube section, is approximately achieved.

The deflections of the middle edge point located on the front and back faces obtained from the side-view highspeed images are shown in Fig. 9. Prior to $400 \mu \mathrm{s}$, the deflections of all panels are almost identical. After $400 \mu \mathrm{s}$, the specimens with the 0 and $15 \mathrm{kN}$ compressive loading have similar deflections while the deflection of the specimen with the $25 \mathrm{kN}$ compressive loading is higher. This indicates that only at high in-plane compressive loading level $(25 \mathrm{kN}, 33 \%$ of the critical load of the

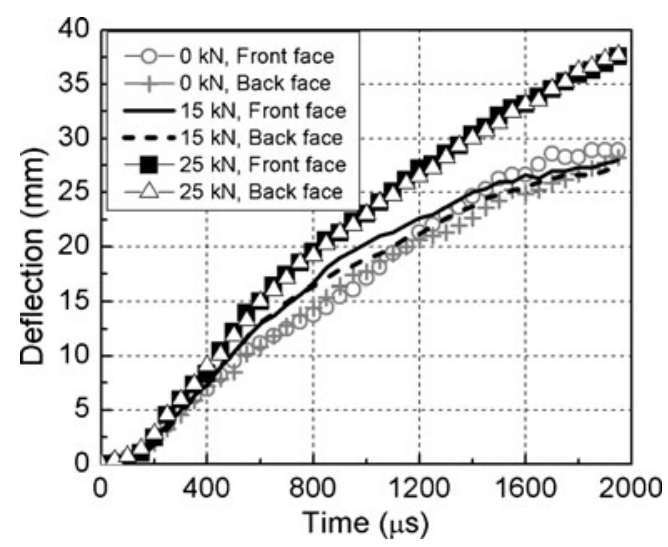

Fig. 9 Deflections of middle edge point at back and front faces of the sandwich composites 
structure buckling) will the deflections along the middle line of the face sheets be significantly affected. Moreover, the middle edge point deflections of the front and back faces for each panel are almost overlapping. This means that there is negligible core compression in the core thickness along the middle line (symmetry line), though there were obvious compressive regions in the core around the buckling area of the core, near to the front face.

\section{Real-time Back-view DIC Results}

Figure 10 shows the back face out-of-plane ( $z$ direction) deflection contours of sandwich composites subjected to blast loading with different levels of initial compressive loading from the DIC analysis. The support knife edges are located at the top and bottom of the images and parallel to the $x$ direction. The color stripes, which are parallel to the support line, show that the deflections of the points through the width of the panels are almost identical. This indicates that the specimens acted like a beam under the current support conditions. It can also be seen that the deflections of the specimens without compressive loading $(0 \mathrm{kN})$ are comparable with the $15 \mathrm{kN}$ compressive loading specimens, with the compressed specimens showing larger deflection after $800 \mu \mathrm{s}$. The specimen with the $25 \mathrm{kN}$ compressive loading has higher deflections.

The in-plane strains $\mathrm{e}_{\mathrm{yy}}$ of the center point (o point) on the back face from the DIC technique are shown in Fig. 11. Here, the vertical direction is the $y$ axis. It can be clearly seen that the trend of the in-plane strains is much different from that of the out-of-plane deflections. Though the deflections are almost identical, the back-face in-plane strain of the specimen with the $15 \mathrm{kN}$ compressive loading is much higher than the one without compressive loading.

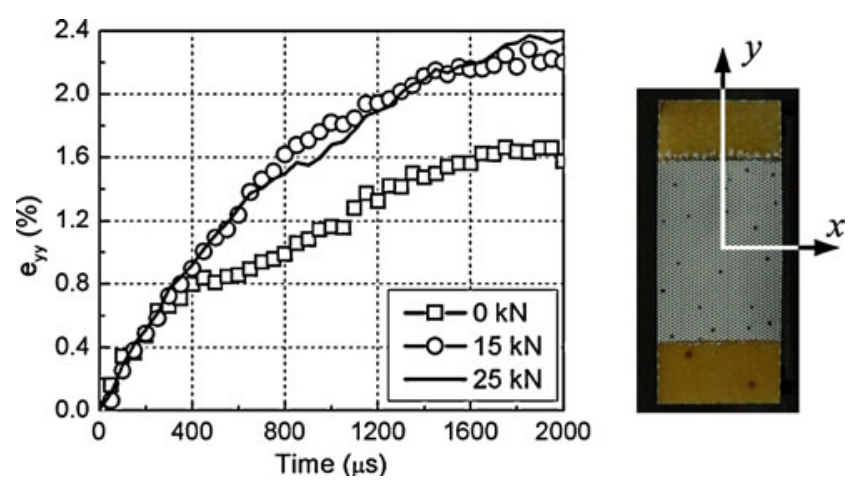

Fig. 11 In-plane strain on the back face at the center point

This is due to the different failure modes of the specimens under different in-plane compressive loading. The in-plane strain $e_{y y}$ on the back face sheet depends on the loads transmitted from two physical mechanisms: the deformation of the core itself and the global bending of the sandwich structure. Due to the constitutive behavior of the core foam material (the stress plateau after the yield point), the load transmitted to the back face sheet by the core has a limit value. However, the load transmitted by the interfaces is most likely based on the global deflection of the sandwich structure, which means this load will keep increasing as long as the interfaces do not totally delaminate. After delamination this load will drop and affect the in-plane strain on the back face sheets. Therefore, in the beginning with small global deflection i.e. prior to $400 \mu$ s, the effects of the core and the interfaces are comparable. When the core cracks appear in the specimen without in-plane load around this time, there is an obvious drop in the $\mathrm{e}_{y y}$ verses time curve. On the other hand, the global bending of the sandwich structure tends to increase the in-plane strain. The
Fig. 10 Out-of-plane deflection contours of sandwich composites subjected to blast loading with in-plane compressive loadings
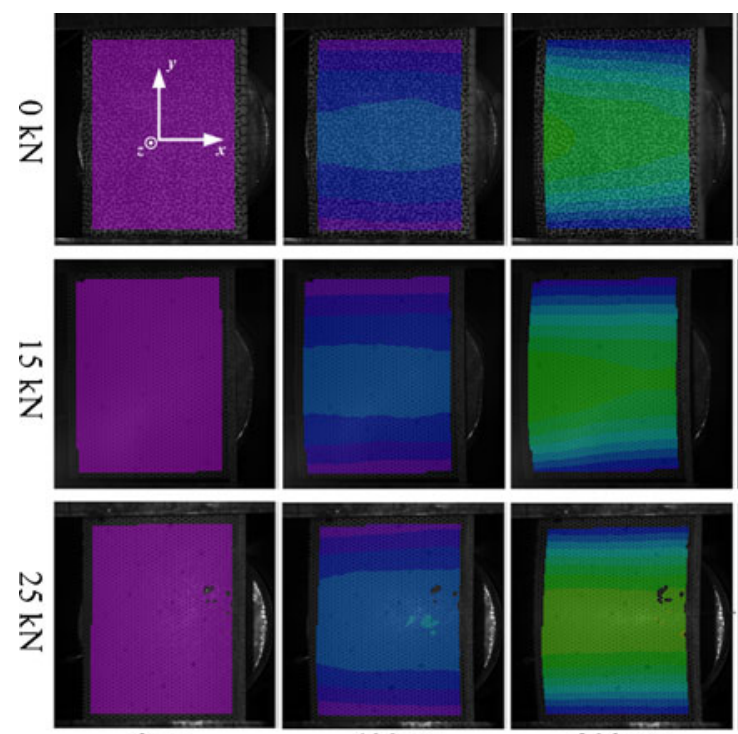

$0 \mu \mathrm{s}$

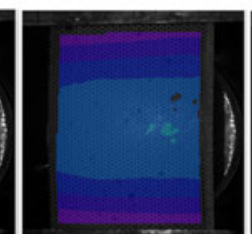

$400 \mu \mathrm{s}$
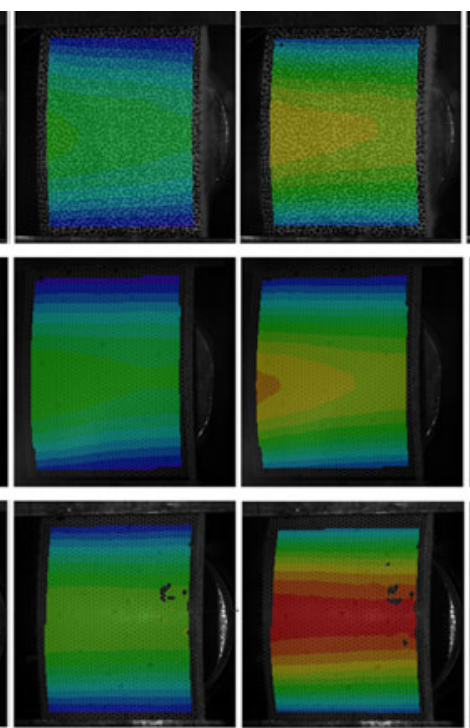

$800 \mu \mathrm{s}$

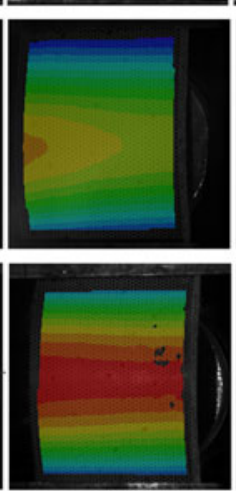

$1200 \mu \mathrm{s}$

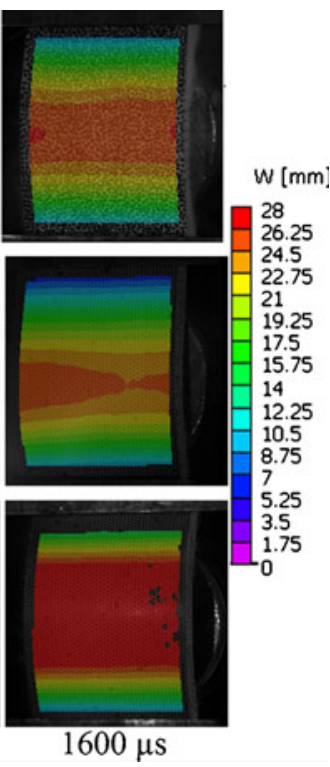


Fig. 12 Post mortem images of sandwich composite with different compressive loading
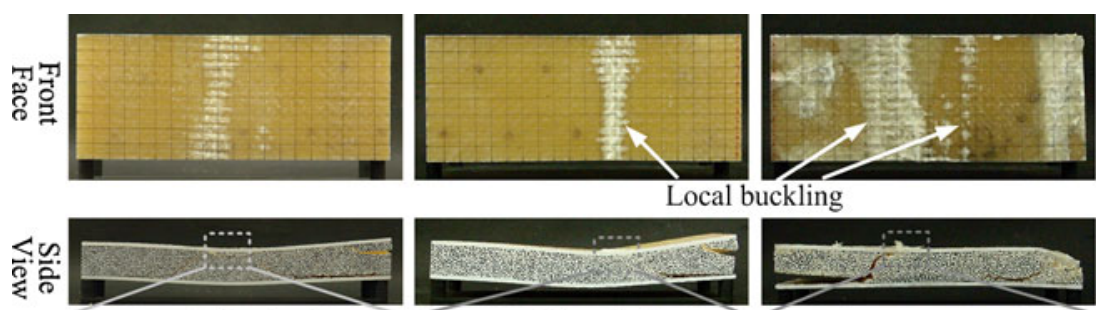

Local buckling
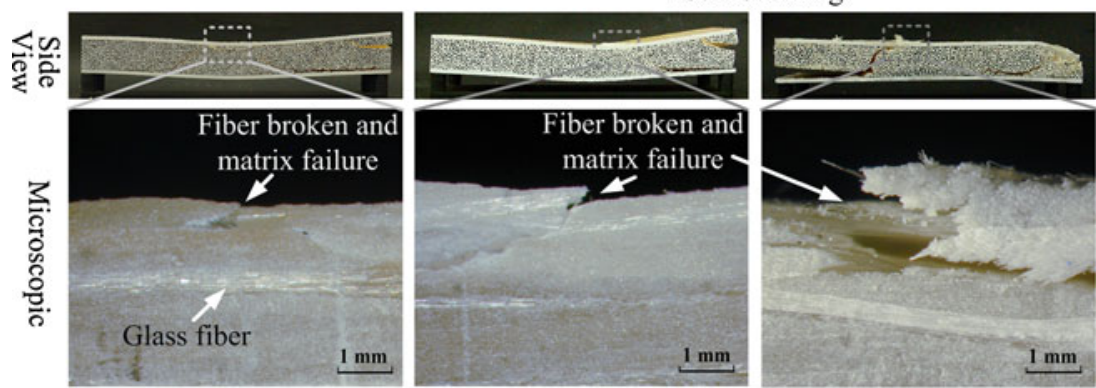

$0 \mathrm{kN}$

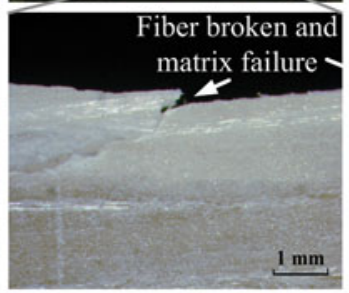

$15 \mathrm{kN}$

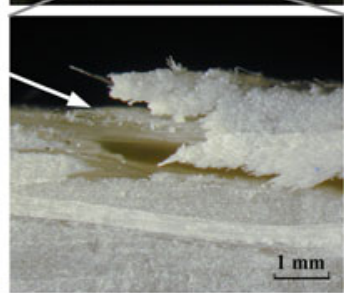

$25 \mathrm{kN}$ combined effect causes the in-plane strain $\mathrm{e}_{y y}$ to keep increasing with a smaller slope after initial drop. For the specimens with $15 \mathrm{kN}$ and $25 \mathrm{kN}$ loadings, the core cracks appeared much later $(1,200 \mu \mathrm{s}$ and $900 \mu \mathrm{s}$, respectively) with a relatively large global deflection. This implies when the core cracks appear, their effect will be small and not that obvious. It can be clearly seen in Fig. 11 the in-plane strain curves have small kinks around 1,200 $\mu$ s and $900 \mu$ s for the specimen with $15 \mathrm{kN}$ and $25 \mathrm{kN}$ in-plane loadings, respectively. These kinks mean that the core cracks do affect the in-plane strain on the back face sheet, but the effect is not as strong as when the core cracks appeared at $400 \mu s$. Two other features are significant in the strain plots. First, prior to $400 \mu \mathrm{s}$ the strain $\mathrm{e}_{\mathrm{yy}}$ of the back face sheet is almost identical for the specimens with and without in-plane loadings. The reason has been mentioned in discussion of Fig. 8 that the specimens with different levels of compressive loading have similar deformation modes during this time period. Second, the in-plane strains of the specimens with $15 \mathrm{kN}$ and $25 \mathrm{kN}$ in-plane loading are comparable during the whole time period until 2,000 $\mathrm{s}$ while they have different back face deflections (see Fig. 9). This is because the specimen with $15 \mathrm{kN}$ in-plane loading has one crack in the core while the specimen with $25 \mathrm{kN}$ inplane loading has two cracks which means the latter should have less effect on the in-plane strain of the back face sheet. Therefore, though the deflection of the specimen with $25 \mathrm{kN}$ in-plane loading is larger, the combined effect of the damage in the core and the global bending makes the inplane strain of the back face comparable with that of the specimen with $15 \mathrm{kN}$ in-plane loading.

\section{Post Mortem Analysis}

The damage patterns of the sandwich composites after the shock loading were visually examined and recorded using a high resolution digital camera and are shown in Fig. 12.
Since the back face sheets do not show any change after the experiments, they are not shown here.

From the front face-sheet images, the local buckling positions are apparent. Note the yellow color is the original color of the specimen and the white color signifies fiber delamination and face-sheet buckling. For the specimen with the $0 \mathrm{kN}$ compressive loading, there is only slight fiber delamination on the front face. From the side-view high-speed images, the front face of the specimen with the $0 \mathrm{kN}$ compressive loading shows a profile with a smooth curvature during the whole shock loading process. Therefore, the delamination is due to the large deflection bending of the sandwich panel during the dynamic loading process. For the specimen with the $15 \mathrm{kN}$ compressive loading, there is a region of heavy fiber delamination on the front face that correlates to the buckling section with large curvature in the side-view high-speed images. For the panel with the $25 \mathrm{kN}$ compressive loading, heavy fiber delamination and buckling occurred at two positions on both sides of the center of the specimen that correlates to the two kinks in the side-view high-speed images. The white area at the end of the specimen is not due to local buckling induced by the compressive loading but is due to a collision between the specimen and the shock tube during the large deflection bending process of the specimen that occurs much later in the event

From the side view post mortem images, the permanent back face sheet deflection of the specimen with the $0 \mathrm{kN}$

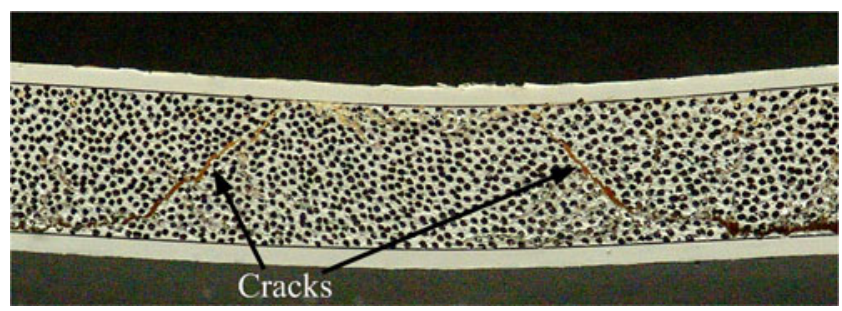

Fig. 13 A close view of the closed cracks of the panel without inplane loading 


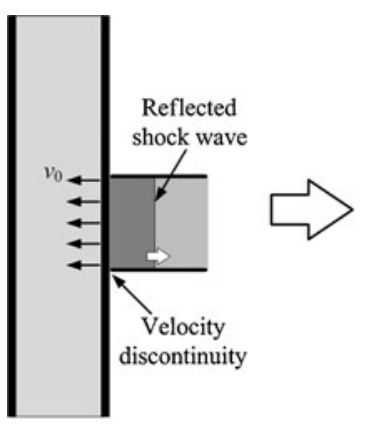

(a)

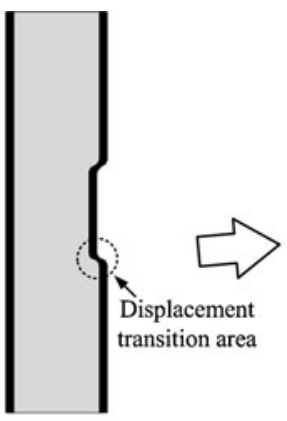

(b)

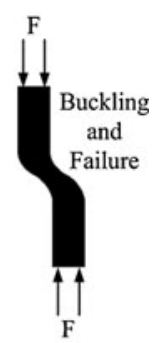

(c)

Fig. 14 A sketch of the response and failure process of sandwich composites under in-plane compressive loading and transverse shock wave loading

compressive loading $(3.4 \mathrm{~mm})$ is less than that of the specimen with the $15 \mathrm{kN}$ compressive loading $(4.8 \mathrm{~mm})$. The specimen with the $25 \mathrm{kN}$ compressive loading showed heavy delamination between the core and back face sheet, which released the stress in the back face sheet. Thus, it showed the least permanent back face sheet deflection. It should be noted that the opened cracks in the core of the specimen without in-plane loading (Fig. 8) almost closed after the experiment as shown in Fig. 13. This shows that the core has an ability to stand large shear deformation.

Microscopic analysis of the buckling region observed in the sandwich panels was done using a Nikon SMZ microscope. These micro images are shown in Fig. 12. For the specimen with the $0 \mathrm{kN}$ compressive loading only a small crack appears in the front face when delamination occurred. For the specimen with $15 \mathrm{kN}$ compressive loading, the crack crossed the first two fiber layers of the front face sheet. For the specimen with the $25 \mathrm{kN}$ compressive loading, the crack had completely opened and propagated into the face sheet by more than half of its thickness. The edge of the crack shows evidence of tearing.

\section{Failure Mechanisms}

The experimental results show that compressive loading significantly affects the blast performance of sandwich

composites. Failure and buckling occurred at specific positions on the front face sheet. In this section, a qualitative model is described to explain the dynamic failure process of sandwich composites with compressive loadings.

A sketch of the response and failure process of sandwich composites under in-plane compressive loadings when they are subjected to transverse shock wave loading is shown in Fig. 14. When the shock wave first impinges on the sandwich panel, it gives an initial velocity field to the front face [24]. Since the loading area is smaller than the front face area, the front face will have different velocities at different locations, as shown in Fig. 14(a). This velocity difference will create some transition areas around the loading area due to the displacement difference after a very short time period, as shown in Fig. 14(b). Then, the flat shape of the front face is destroyed. The in-plane compressive loading on the front face generates shear loading at the transition areas as shown Fig. 14(c). This shear loading significantly reduces the critical buckling load of the front face and reduces the blast resistance of the sandwich composite.

Correlation between the high-speed side-view images with post mortem images for the three compressive loading states is shown in Fig. 15. The lines show the boundaries of the shock loading area. It can be clearly seen that the failure positions on the front face of the sandwich panels are located around the boundaries of the shock loading area. These areas are the transition areas seen in Fig. 14(b).

In experiments, the failure areas are not symmetric to the loading area though the transition areas are. This is because the loading, support and the composite material properties may not be perfect. The failure always occurred at one transition position first. Subsequent to this, if the in-plane compressive loading was not high enough, the second buckling site does not develop and the loading applied on the symmetric position of the front face was released. Thus, there is only one failure position on the front face [Fig. 15 (b)]. If the in-plane compressive loading is high enough, as is the case with the $25 \mathrm{KN}$ loading, another failure site develops before loading is totally released as seen on the front face of Fig. 15(c).
Fig. 15 Failure positions for the sandwich panel with different compressive loadings

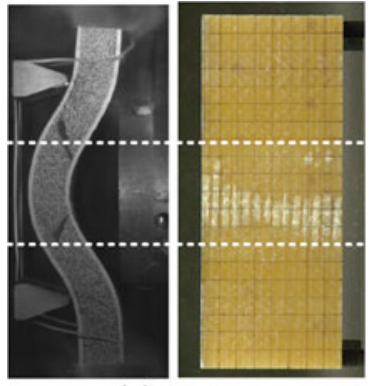

(a) $0 \mathrm{kN}$

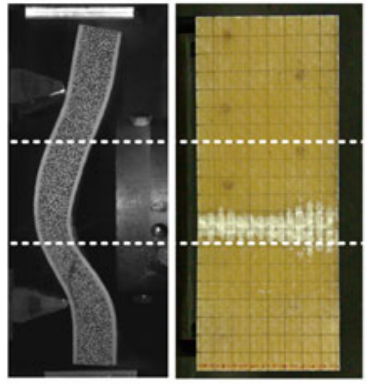

(b) $15 \mathrm{kN}$

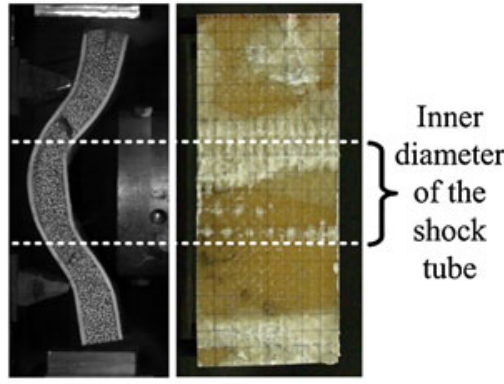

(c) $25 \mathrm{kN}$ 


\section{Closure}

Sandwich composites, with E-glass Vinyl Ester composite face sheet and CoreCell ${ }^{\mathrm{TM}}$ P600 foam core, were put under an in-plane compressive loading prior to being subjected to a transverse shock wave loading. Three levels of compressive loading, $0 \mathrm{kN}, 15 \mathrm{kN}$ and $25 \mathrm{kN}$, were chosen to study the effect of the uni-aixal in-plane loading on the dynamic behavior of the sandwich composites. A high-speed photography system and a 3-D Digital Image Correlation (DIC) technique were utilized to obtain full-field deformation data. The results showed that the in-plane compressive loading coupled with the transverse blast loading induced local buckling in the front face sheet of the sandwich composites. Higher levels of compressive loading caused more damage in the front face sheet, larger out-of-plane deflection, and higher in-plane strain on the back face sheet. Consequently, the over-all blast resistance of sandwich composites was significantly reduced. A qualitative model was proposed to show that the transverse shock wave created displacement transition regions in the front face due to the fluid-structure interaction. These displacement transition regions fail easily due to local buckling under in-plane compressive loading. This mechanism highly reduces the blast resistance of the sandwich composites.

Acknowledgement The authors acknowledge the financial support provided by Dr. Yapa D. S. Rajapakse, under Office of Naval Research Grant No. N00014-04-1-0268and the support provided by the Department of Homeland Security under Cooperative Agreement No. 2008-ST-061-ED0002. The authors also thank Dr. Stephen Nolet and TPI Composites for providing their facility to fabricate the sandwich materials. Thanks to Gurit SP Technology and Speciality Products Incorporated for providing the core material used in this study.

\section{References}

1. Yao T (2003) Hull girder strength. Mar struct 16:1-13

2. Nurick GN, Langdon GS, Chi Y, Jacob N (2009) Behavior of sandwich panels subjected to intense air blast-part 1: experiments. Compos Struct 91(4):433-441

3. Zhu F, Zhao L, Lu G, Wang Z (2008) Deformation and failure of blast loaded metallic sandwich panels - experimental investigations. Int J Impact Eng 35(8):937-951

4. Dharmasena KP, Wadley HNG, Xue Z, Hutchinson JW (2008) Mechanical response of metallic honeycomb sandwich panel structures to high-intensity dynamic loading. Int J Impact Eng 35(9):1063-1074
5. Radford DD, McShane GJ, Deshpande VS, Fleck NA (2006) The response of clamped sandwich plates with metallic foam cores to simulated blast loading. Int J Solids Struct 44:6101-6123

6. Tekalur SA, Bogdanovich AE, Shukla A (2008) Shock loading response of sandwich panels with 3-D woven E-glass composite skins and stitched foam core. Compos Sci Technol 69(6):736-753

7. Wang E, Gardner N, Shukla A (2009) The blast resistance of sandwich composites with stepwise graded cores. Int J Solids Struct 46:3492-3502

8. Shukla A, Ravichandran G, Rajapakse YDS (2009) Dynamic failure of materials and structures. Springer, New York. ISBN $144190445 \mathrm{X}$

9. Robb MD, Arnold WS, Marshall IH (1995) The damage tolerance of GRP laminates under biaxial prestress. Compos Struct 32:141149

10. Whittingham B, Marshall IM, Mitrevski T, Jones R (2004) The response of composite structures with pre-stress subject to low velocity impact damage. Compos Struct 66:685-698

11. Heimbs S, Heller S, Middendorf P, Hahnel F, Weiße J (2009) Low velocity impact on CFRP plates with compressive preload: test and modeling. Int J Impact Eng 36:1182-1193

12. Sun CT, Chen JK (1985) On the impact of initially stressed composite laminates. J Compos Mater 19:490-504

13. Choi IH (2008) Low-velocity impact analysis of composite laminates under initial in-plane load. Compos Struct 86:251257

14. Cost TL, Jones HW (1979) Dynamic response of blast loaded prestressed flat plates. J Sound Vib 62(1):111-120

15. Chen FL, Yu TX (2000) Influence of axial pre-load on plastic failure of beams subjected to transverse dynamic load. Adv Eng Plasticity 177(1):255-260

16. http:/www.gurit.com/page.asp?section $=00010001002200160010 \&$ sectionTitle $=$ Corecell $\% 99+\mathrm{P} \% 2 \mathrm{DF}$ oam $+\% 2 \mathrm{D}+$ Heat + stabilised + for + prepreg+processes, Accessed 13 Dec 2010

17. Fleck NA, Sridhar I (2002) End compression of sandwich columns. Compos A 33:353-359

18. Mamalis AG, Manolakos DE, Ioannidis MB, Papapostolou DP (2005) On the crushing response of composite sandwich panels subjected to edgewise compression: experimental. Compos Struct $71: 246-257$

19. Shukla A, Dally JW (2010) Experimental solid mechanics. College House Enterprises, LLC, Knoxville

20. Sutton MA, Orteu JJ, Schreier H (2009) Image correlation for shape, motion and deformation measurements: basic concepts, theory and applications. Springer, New York, ISBN-10: 0387787461, ISBN-13: 978-0387787466

21. Tiwari V, Sutton MA, McNeill SR, Xu S, Deng X, Fourney WL, Bretall D (2009) Application of 3D image correlation for full-field transient plate deformation measurements during blast loading. Int J Impact Eng 36:862-874

22. Chu TC, Ranson WF, Sutton MA (1985) Applications of digitalimage-correlation techniques to experimental mechanics. Exp Mech 25(3):232-244

23. Wang E, Shukla A (2010) Analytical and experimental evaluation of energies during shock wave loading. Int J Impact Eng 37:11881196

24. Fleck NA, Deshpande VS (2004) The resistance of clamped sandwich beams to shock loading. J Appl Mech 71:386-401 